\title{
The protective and hemodynamic effects of dexmedetomidine on hypertensive cerebral hemorrhage patients in the perioperative period
}

\author{
JUNHUI ZHAO ${ }^{1 *}$ and CHUIXIAN ZHOU ${ }^{2 *}$ \\ ${ }^{1}$ Department of Anesthesiology, Weifang Medical University, Weifang, Shandong 261053; \\ ${ }^{2}$ Department of Neurosurgery, Weifang People's Hospital, Weifang, Shandong 261041, P.R. China
}

Received March 2, 2016; Accepted September 13, 2016

DOI: $10.3892 /$ etm.2016.3711

\begin{abstract}
The aim of the present study was to analyze the protective and hemodynamic effects of dexmedetomidine in hypertensive cerebral hemorrhage $(\mathrm{HCH})$ patients during perioperative period. In total, $50 \mathrm{HCH}$ patients were selected and randomly divided into two groups, one group was administered with dexmedetomidine and the other groups with midazolam. The mean arterial pressure (MAP), heart rate $(\mathrm{HR})$ and blood oxygen saturation $\left(\mathrm{SpO}_{2}\right)$ were monitored in the two groups of patients before and during the operation. The MAP, $\mathrm{HR}, \mathrm{SpO}_{2}$ and $\mathrm{P}_{\mathrm{ET}} \mathrm{CO}_{2}$ recorded $5 \mathrm{~min}$ after admission into the operation room was considered $\mathrm{T}_{1}$, the same parameters recorded 10 min after drug administration were considered $\mathrm{T}_{2}$, just after starting the operation were considered $\mathrm{T}_{3}$ and $30 \mathrm{~min}$ after start of operation were considered $\mathrm{T}_{4}$. The preoperative sedation and analgesia were evaluated by the Ramsay scoring method and the neuron-specific enolase (NSE) and S100 protein (S100 $\beta$ ) were estimated using ELISA. The patients of the midazolam group experienced mild respiratory depression during the period of sedation. Levels of, MAP, $\mathrm{HR}$ and $\mathrm{P}_{\mathrm{ET}} \mathrm{CO}_{2}$ were significantly increased whereas $\mathrm{SPO}_{2}$ was decreased $(\mathrm{P}<0.05)$. The MAP, $\mathrm{HR}, \mathrm{SPO}_{2}$ and $\mathrm{P}_{\mathrm{ET}} \mathrm{CO}_{2}$ were stable during the period of sedation $(\mathrm{P}>0.05)$. The plasma concentrations of epinephrine and norepinephrine at $\mathrm{T}_{1}$ were similar in the two groups $(\mathrm{P}>0.05)$, but decreased after drug administration. This decrease was more prominent in the dexmedetomidine group patients $(\mathrm{P}<0.05)$ than midazolam group patients. The epinephrine and norepinephrine concentrations just after starting
\end{abstract}

Correspondence to: Dr Junhui Zhao, Department of Anesthesiology, Weifang Medical University, 7166 Baotong West Street, Weifang, Shandong 261053, P.R. China

E-mail: zhao_junhui1@163.com

${ }^{*}$ Contributed equally

Key words: dexmedetomidine, hemodynamic, hypertensive cerebral hemorrhage, perioperative period operation $\left(\mathrm{T}_{3}\right)$ were higher than the basal level $\left(\mathrm{T}_{1}\right)$ in the midazolam group, but close to the basal level in the dexmedetomidine group $(\mathrm{P}<0.05)$. The serum concentration of NSE and $\mathrm{S} 100 \beta$ in the two groups showed no difference $(\mathrm{P}>0.05)$ at the end of operation $\left(\mathrm{T}_{5}\right)$, but after $24 \mathrm{~h}$ of operation $\left(\mathrm{T}_{7}\right)$ NSE and S100 $\beta$ in the dexmedetomidine group were significantly lower compared to the midazolam group $(\mathrm{P}<0.05)$. In conclusion, the administration of dexmedetomidine for patients with $\mathrm{HCH}$ during perioperative period is safe and serves as an effective sedative, without causing respiratory depression and does not influence stable haemodynamics with certain brain protective effect.

\section{Introduction}

Hypertensive cerebral hemorrhage $(\mathrm{HCH})$ is a serious threat to human health, causing high mortality and morbidity (1). The oppression on the surrounding brain tissue caused by hematoma can be removed through surgical resection by relieving secondary brain injury and this method, known as brain hematoma clearance, as well as decompressive craniectomy are widely used in clinical settings (2). During the perioperative period, the body's stress response can be effectively reduced by the rational use of sedative to prevent blood pressure fluctuations that cause secondary bleeding. However, traditional sedatives and analgesic drugs such as benzodiazepines or opioid are often insufficient to lead to sedative and analgesic effects (3).

The administration of a high dose of these drugs lead to excessive sedation and respiratory depression, thereby affecting circulatory and respiratory functions and becoming life threatening. Dexmedetomidine is a novel $\alpha_{2}$ adrenoceptor agonist with high selectivity that can produce a good sedative effect. Furthermore, the sympathetic resistance effect of this drug, decreases the sympathetic excitation caused by surgery and anesthesia and thus helps the stability of haemodynamics. The drug also has certain neuroprotective effects such as, easy wake up after sedation and prevention of respiratory depression (4). Considering the above facts, we have analyzed the suitability of the administration of dexmedetomidine as a sedative and analgesic for patients with $\mathrm{HCH}$ during the perioperative period. 


\section{Materials and methods}

Subjects. All 50 cases of the present study were $\mathrm{HCH}$ patients from the Department of Neurosurgery of the Weifang Brain Hospital (Weifang Medical University, Weifang, China) and were scheduled to undergo intracranial hematoma clearance combined with decompressive craniectomy, according to the American Stroke Association level I or II with an age range of 29-68 years.

The inclusion criteria for the study were: i) The patients were confirmed with $\mathrm{HCH}$ by brain computed tomography (CT) in accordance with the clinical diagnostic criteria of the Fourth National Society of Cerebrovascular Diseases; ii) Glasgow scoring $\geq 12$ points; iii) initial CT displayed supratentorial hematoma $\geq 30 \mathrm{ml}$. Exclusion criteria for the study were: i) Clear evidence that bleeding was caused by cerebral aneurysms, arteriovenous malformations, brain injury, or tumor stroke; ii) subtentorial cerebral hemorrhage; iii) advanced cerebral hernia, bilateral pupil divergence, and decerebrate rigidity; iv) combined with history of severe primary diseases, such as cardiovascular disease, kidney disease, diabetes, hepatopathy or mental retardation, and history of analgesic drugs.

The present study was approved by the ethics committee of the Weifang People's Hospital. Witten informed consent of the patients was obtained.

Chemicals and analyses. Dexmedetomidine hydrochloride and midazolam hydrochloride injection were commercially obtained (Tocris Bioscience, Bristol, UK). The catecholamine (Rocky Mountain Diagnostics, Colorado Springs, CO, USA), neuron-specific enolase (NSE) and S100 $\beta$ (S100 $\beta$ protein) were estimated using ELISA as per instructions the manufacturer's (Rocky Mountain Diagnostics).

Patient monitoring. Sedation and analgesia were observed before and after surgery in the dexmedetomidine and midazolam groups, combined with electrocardiogram (ECG) monitoring.

The intra-surgical hemodynamics was also monitored in the dexmedetomidine and midazolam groups. Briefly, the mean arterial pressure (MAP), heart rate (HR), blood oxygen saturation $\left(\mathrm{SpO}_{2}\right)$ and ECG were monitored in patients prior to surgery. Approximately, $30 \mathrm{~min}$ before anesthesia, the patients were administered with an intramuscular injection of $100 \mathrm{mg}$ phenobarbital sodium and $0.5 \mathrm{mg}$ atropine. MAP, $\mathrm{HR}, \mathrm{SPO}_{2}$ and $\mathrm{P}_{\mathrm{ET}} \mathrm{CO}_{2}$ at 5 min after admission to the operation room $\left(\mathrm{T}_{1}\right), 10$ min after drug administration $\left(\mathrm{T}_{2}\right)$, just after starting operation $\left(\mathrm{T}_{3}\right)$ and $30 \mathrm{~min}$ after the start of operation $\left(\mathrm{T}_{4}\right)$ were recorded.

Administration of drugs. Prior to the anesthesia induction, $1 \mu \mathrm{g} / \mathrm{kg}$ dexmedetomidine was diluted in normal saline to a final volume of $20 \mathrm{ml}$ and administered to patients via pump infusion for $10 \mathrm{~min}$ (dexmedetomidine group). Then, $0.05 \mathrm{mg} / \mathrm{kg}$ midazolam was diluted in normal saline to a final volume of $20 \mathrm{ml}$ and administered to patients via pump infusion for $10 \mathrm{~min}$ (midazolam group). The two groups were given tracheal intubation general anesthesia. Anesthesia induction was performed with fentanyl $(4 \mu \mathrm{g} / \mathrm{kg})$, propofol $(2 \mathrm{mg} / \mathrm{kg})$ and rocuronium $(1 \mathrm{mg} / \mathrm{kg})$, followed by continuous pump infusion
Table I. General characteristics of patients.

\begin{tabular}{lcccc}
\hline Groups & $\begin{array}{c}\text { Age, } \\
\text { years }\end{array}$ & $\begin{array}{c}\text { Weight, } \\
\mathrm{kg}\end{array}$ & $\begin{array}{c}\text { Gender, } \\
\mathrm{m} / \mathrm{f}\end{array}$ & $\begin{array}{c}\text { Operation } \\
\text { time, min }\end{array}$ \\
\hline Midazolam & $55.1 \pm 3.3$ & $69.6 \pm 4.4$ & $14 / 11$ & $173 \pm 11$ \\
Dexmedotomidine & $54.5 \pm 3.0$ & $70.1 \pm 3.5$ & $12 / 13$ & $172 \pm 10$ \\
\hline
\end{tabular}

of propofol $(4-10 \mathrm{mg} / \mathrm{kg} / \mathrm{h})$, fentanyl $(0.1-0.3 \mu \mathrm{g} / \mathrm{kg} / \mathrm{min})$, cisatracurium besilate $(0.1 \mathrm{mg} / \mathrm{kg} / \mathrm{h})$ before the operation and maintained during operation. During operation, the dexmedetomidine group was given $0.5 \mu \mathrm{g} / \mathrm{kg} / \mathrm{h}$ dexmedetomidine via pump infusion while the midazolam group was given $0.05 \mathrm{mg} / \mathrm{kg} / \mathrm{h}$ midazolam via pump infusion.

The patients with blood pressure $30 \%$ below the base level were given $5 \mathrm{mg}$ ephedrine hydrochloride, followed by an additional $0.5 \mathrm{mg}$ if the first dose seemed ineffective. The patients with $\mathrm{HR}<50$ times/min were given $0.5 \mathrm{mg}$ atropine. Patients with blood pressure $20 \%$ above the base value were given $0.1-0.15 \mathrm{mg} / \mathrm{kg}$ urapidil hydrochloride. Dexmedetomidine and midazolam infusion were suspended $30 \mathrm{~min}$ before operation, rocuronium infusion was suspended $10 \mathrm{~min}$ before the end of the operation, and propofol and fentanyl were suspended at the end of the operation.

Intracranial hematoma clearance combined with decompressive craniectomy was performed to treat the enrolled patients. Catheterization via radial artery puncture was employed to monitor the arterial pressure.

The plasma concentration of epinephrine and norepinephrine and the level of NSE and S100 $\beta$ protein in plasma at the end of the operation $\left(\mathrm{T}_{5}\right)$ and $24 \mathrm{~h}$ after the operation $\left(\mathrm{T}_{7}\right)$ were analyzed and recorded.

Observation of indexes. Respiratory depression $\left(\mathrm{SpO}_{2}<90 \%\right.$ and lasted $>20 \mathrm{sec}$ ), bradycardia (HR $<60$ beats/min), hypertension (diastolic blood pressure $>150 \mathrm{mmHg}$ ), hypotension (systolic blood pressure $<90 \mathrm{mmHg}$ ), nausea, vomiting and other adverse reactions were observed and recorded. The MAP, HR, $\mathrm{SpO}_{2}$ and ECG were also observed and recorded. The plasma concentration of epinephrine and norepinephrine during operation was monitored.

Degrees of sedation. The depth of sedation was evaluated using the Ramsay scoring method. Scoring was as follows: 1 point, anxious and agitated; 2 points, sober, quiet and cooperative; 3 points, in quiet sleep and responsive to instructions; 4 points, in sleep, responsive to loudness and sensitive to glabellar tapping or sound sensation; 5 points, in sleep, slow in response to glabellar tapping or sound sensation; and 6 points, in deep sleep or unconsciousness, in a state of anesthesia.

Degree of agitation. The grading standards used were: Level 0 , quiet and cooperative; level 1, mild agitation, limb restlessness under sputum suction stimulation, intermittent groan; level 2, moderate agitation, restlessness when there was no stimulation, continuous groan, and upper limbs in need of fixation; level 3, severe agitation, dramatic body movement, incapable of cooperation. 
Table II. Hemodynamics and respiration.

\begin{tabular}{|c|c|c|c|c|c|c|}
\hline Group & Patients & Time & MAP & HR & $\mathrm{SPO}_{2}(\%)$ & $\mathrm{P}_{\mathrm{ET}} \mathrm{CO}_{2}(\mathrm{mmHg})$ \\
\hline \multirow[t]{4}{*}{ M } & \multirow[t]{4}{*}{25} & $\mathrm{~T}_{1}$ & $125.2 \pm 13.1$ & $80.2 \pm 12.5$ & $99.3 \pm 0.8$ & $42.1 \pm 1.3$ \\
\hline & & $\mathrm{T}_{2}$ & $121.4 \pm 12.8$ & $76.6 \pm 13.9$ & $93.1 \pm 0.7^{\mathrm{a}}$ & $44.6 \pm 1.5^{\mathrm{a}}$ \\
\hline & & $\mathrm{T}_{3}$ & $99.4 \pm 13.7^{\mathrm{a}}$ & $81.4 \pm 12.4^{\mathrm{a}}$ & $98.7 \pm 0.9$ & $41.7 \pm 0.9$ \\
\hline & & $\mathrm{T}_{4}$ & $98.3 \pm 11.4^{\mathrm{a}}$ & $79.9 \pm 13.2^{\mathrm{a}}$ & $99.2 \pm 0.7$ & $37.5 \pm 1.7$ \\
\hline \multirow[t]{4}{*}{$\mathrm{D}$} & \multirow[t]{4}{*}{25} & $\mathrm{~T}_{1}$ & $125.6 \pm 12.8$ & $79.3 \pm 11.5$ & $98.9 \pm 0.8$ & $43.5 \pm 1.7$ \\
\hline & & $\mathrm{T}_{2}$ & $118.9 \pm 13.2$ & $64.9 \pm 13.3$ & $98.2 \pm 0.6$ & $40.4 \pm 1.3$ \\
\hline & & $\mathrm{T}_{3}$ & $89.8 \pm 12.5$ & $65.6 \pm 10.9$ & $99.5 \pm 0.6$ & $38.8 \pm 1.6$ \\
\hline & & $\mathrm{T}_{4}$ & $88.3 \pm 12.6$ & $69.1 \pm 13.8$ & $99.9 \pm 0.2$ & $37.3 \pm 2.0$ \\
\hline
\end{tabular}

${ }^{\mathrm{a}} \mathrm{P}<0.05$, comparison was made against dexmedetomidine group. MAP, mean arterial pressure; HR, heart rate; $\mathrm{SPO}_{2}$, blood oxygen saturation.

Specificity and sensitivity indexes of cerebral protection. During operation, the level of NSE and S100 $\beta$ protein were monitored using ELISA. Detailed protocol was according to a pevious report (5).

Statistical analysis. SPSS 13.0 statistical software (SPSS, Inc., Chicago, IL, USA) was used. The values were presented as mean \pm standard deviation. The independent-samples t-test, analysis of variance, 4 -fold table $\chi^{2}$ test or row x column $\chi^{2}$ test were used to compare and analyze the values of dexmedetomidine and midazolam groups. $\mathrm{P}<0.05$ was considered to indicate a statistically significant difference.

\section{Results}

General characteristics of patients. The age, gender, body weight and operation time between dexmedetomidine and midazolam were not statistically significant $(\mathrm{P}>0.05$, Table I).

Hemodynamics and respiration. After $10 \mathrm{~min}$ of administration $\left(\mathrm{T}_{2}\right)$ of dexmedetomidine or midazolam, the $\mathrm{SpO}_{2}$ of the midazolam group was significantly decreased and $\mathrm{P}_{\mathrm{ET}} \mathrm{CO}_{2}$ was significantly increased in comparison with the dexmedetomidine group $(\mathrm{P}<0.05)$. The MAP and HR of the midazolam group patients, just after the start of the operation $\left(\mathrm{T}_{3}\right)$ and $30 \mathrm{~min}$ after the operation $\left(\mathrm{T}_{4}\right)$ were significantly higher when compared with the dexmedetomidine group $(\mathrm{P}<0.05$, Table II).

Degree of sedation. Approximately 10 min after drug administration $\left(\mathrm{T}_{2}\right)$, sedation in the two groups of patients was deepened. The Ramsay scores in the two groups were significantly elevated $(\mathrm{P}<0.05)$ when compared with their respective base value $\left(\mathrm{T}_{1}\right)$. The degree of sedation was not significantly different between the dexmedetomidine and midazolam groups ( $\mathrm{P}>0.05$, Table III).

Plasma concentration of epinephrine and norepinephrine. The concentrations of epinephrine and norepinephrine was not significantly different between the dexmedetomidine and midazolam groups at $\mathrm{T}_{1}(\mathrm{P}>0.05)$. After drug infusion $\left(\mathrm{T}_{2}\right)$, epinephrine and norepinephrine of the dexmedetomi-
Table III. Degree of sedation.

\begin{tabular}{lccc}
\hline Group & Patients & Time point & Ramsay score \\
\hline M & 25 & $\mathrm{~T}_{1}$ & $1.8 \pm 0.8$ \\
& & $\mathrm{~T}_{2}$ & $3.3 \pm 0.3^{\mathrm{a}, \mathrm{b}}$ \\
$\mathrm{D}$ & 25 & $\mathrm{~T}_{1}$ & $1.9 \pm 0.9$ \\
& & $\mathrm{~T}_{2}$ & $3.5 \pm 0.5^{\mathrm{a}}$ \\
\hline
\end{tabular}

${ }^{\mathrm{a}} \mathrm{P}<0.05$, comparison between $\mathrm{T}_{1}$ and $\mathrm{T}_{2} ;{ }^{\mathrm{b}} \mathrm{P}>0.05$, comparison between groups. $\mathrm{M}$, midazolam; $\mathrm{D}$, dexmedotomidine.

dine group were significantly reduced when compared with the midazolam group $(\mathrm{P}<0.05)$. The two groups of patients achieved a significant reduction in the concentration of epinephrine and norepinephrine at $\mathrm{T}_{2}$ when compared to their respective base values at $\mathrm{T}_{1}(\mathrm{P}<0.05)$. Shortly after starting the operation $\left(\mathrm{T}_{3}\right)$, the plasma concentration of epinephrine and norepinephrine of the midazolam group were significantly elevated to different degrees (Table IV) in comparison with their respective base values at $T_{1}$. During the same period $\left(\mathrm{T}_{3}\right)$, epinephrine and norepinephrine of the dexmedetomidine group was significantly lower in comparison with midazolam group $(\mathrm{P}<0.05)$. Approximately $30 \mathrm{~min}$ after the start of the operation $\left(\mathrm{T}_{4}\right)$, epinephrine and norepinephrine returned to normalcy in the dexmedetomidine group, whereas, epinephrine and norepinephrine were higher than base level at $\mathrm{T}_{1}$ in the midazolam group (Table IV).

Levels of NSE and S100 $\beta$. The levels of NSE and S100 $\beta$ between different time points $\left(\mathrm{T}_{1}\right.$ and $\left.\mathrm{T}_{5}\right)$ within the group and between the groups were not statistically significant $(\mathrm{P}>0.05)$. However, at $\mathrm{T}_{7}$ (24 $\mathrm{h}$ after operation), NSE and $\mathrm{S} 100 \beta$ levels of the midazolam group were significantly higher than those of the dexmedetomidine group $(\mathrm{P}<0.05$, Table $\mathrm{V})$.

Degree of agitation. At the time of tracheal extubation $\left(\mathrm{T}_{6}\right)$, a significant number of patients of the dexmedetomidine group were quite relatively cooperative and the patients with agitation were fewer in comparison with the midazolam group $(\mathrm{P}<0.05$, Table VI). 
Table IV. Plasma concentration of epinephrine and norepinephrine.

\begin{tabular}{lccccc}
\hline Parameter & Group & \multicolumn{1}{c}{$\mathrm{T}_{1}$} & \multicolumn{1}{c}{$\mathrm{T}_{2}$} & $\mathrm{~T}_{3}$ & $\mathrm{~T}_{4}$ \\
\hline Epinephrine & $\mathrm{M}$ & $0.14 \pm 0.01$ & $0.11 \pm 0.03$ & $0.21 \pm 0.02$ & $0.15 \pm 0.04$ \\
& $\mathrm{D}$ & $0.14 \pm 0.02$ & $0.06 \pm 0.02^{\mathrm{a}, \mathrm{b}}$ & $0.14 \pm 0.04^{\mathrm{a}}$ & $0.12 \pm 0.01$ \\
Norepinephrine & $\mathrm{M}$ & $0.36 \pm 0.03$ & $0.30 \pm 0.01$ & $0.47 \pm 0.01^{\mathrm{a}}$ & $0.40 \pm 0.03$ \\
& $\mathrm{D}$ & $0.34 \pm 0.02$ & $0.25 \pm 0.03^{\mathrm{a}, \mathrm{b}}$ & $0.38 \pm 0.02^{\mathrm{b}}$ & $0.35 \pm 0.01$ \\
\hline
\end{tabular}

${ }^{\mathrm{a}} \mathrm{P}<0.05$, compared with $\mathrm{T}_{1}$; ${ }^{\mathrm{b}} \mathrm{P}<0.05$, compared with midazolam group. $\mathrm{M}$, midazolam; $\mathrm{D}$, dexmedetomidine.

Table V. Levels of NSE and S100ß.

\begin{tabular}{lllll}
\hline Parameters & \multicolumn{1}{c}{ Group } & $\mathrm{T}_{1}$ & $\mathrm{~T}_{5}$ & $\mathrm{~T}_{7}$ \\
\hline $\mathrm{NSE}(\mu \mathrm{g} / \mathrm{ml})$ & Dexmedetomidine & $10.0 \pm 1.2$ & $12.3 \pm 1.6$ & $17.9 \pm 2.27$ \\
& Midazolam & $10.2 \pm 1.7$ & $13.2 \pm 1.7$ & $28.4 \pm 2.28^{\mathrm{a}}$ \\
$\mathrm{S} 100 \beta(\mu \mathrm{g} / \mathrm{ml})$ & Dexmedetomidine & $0.25 \pm 0.12$ & $2.24 \pm 0.74$ & $1.09 \pm 0.43$ \\
& Midazolam & $0.26 \pm 0.11$ & $2.49 \pm 0.70$ & $1.62 \pm 0.44^{\mathrm{a}}$ \\
\hline
\end{tabular}

${ }^{a} \mathrm{P}<0.05$, compared with dexmedetomidine group. NSE, neuron specific enolase.

Table VI. Degree of agitation.

\begin{tabular}{lcccc}
\hline & \multicolumn{4}{c}{ Scores } \\
\cline { 2 - 5 } Group & $0(\mathrm{n})$ & $1(\mathrm{n})$ & $2(\mathrm{n})$ & $3(\mathrm{n})$ \\
\hline Dexmedetimodine & $22^{\mathrm{a}}$ & $2^{\mathrm{a}}$ & 0 & 1 \\
Midazolam & 17 & 5 & 1 & 2
\end{tabular}

${ }^{\mathrm{a}} \mathrm{P}<0.05$, compared with the midazolam group.

\section{Discussion}

Dexmedetomidine is a novel highly selective $\alpha_{2}$-adrenergic receptor agonist with a good sedative effect and without respiration inhibition effect $(6,7)$. Previous findings have shown that $\alpha_{2}$ adrenergic receptors widely exist in the central nervous system, peripheral nervous system (somatic nerves and autonomic nerves) and autonomic ganglion, especially in tissues or organs dominated by sympathetic afferent nerves, such as vascular smooth muscle (8). A previous study has found that the $\alpha_{2}$ adrenergic receptor has three different receptor subtypes: $\alpha_{2 \mathrm{~A}}, \alpha_{2 \mathrm{~B}}$ and $\alpha_{2 \mathrm{C}}$ receptor (9). The receptors can connect with $\mathrm{G}$ protein and have a total of seven transmembrane segments that can couple with G0/G1 signal system and, inhibit the activation of adenylate cyclase activity and synthesis of cAMP, as well as inhibit the calcium channel and activate the potassium channel. Their different distribution determines their different functions.

The $\alpha_{2 \mathrm{~B}}$ receptors are mainly distributed in thalamus while $\alpha_{2 \mathrm{~A}}$ and $\alpha_{2 \mathrm{C}}$ receptors are widely distributed in the brain. The $\alpha_{2 \mathrm{~A}}$ receptors are highly distributed in the locus coeruleus area and may inhibit the activity of norepinephrine cells of these regional brain tissues. $\alpha_{2 \mathrm{~A}}$ receptors exist in the anterior and posterior synapsis and could inhibit the release of norepinephrine and the activity of sympathetic nerve cells (8). Dexmedetomidine (8) may inhibit the generation of cGMP in a dose-dependent manner. Furthermore, $\alpha_{2 \mathrm{~A}}$ receptors play an important role in the main pharmacological and therapeutic effects of dexmedetomidine. From experiments on mice, it was found that when $\alpha_{2 \mathrm{~A}}$ receptors were blocked, the sedation, anesthesia and analgesic effects of dexmedetomidine disappeared but when $\alpha_{2 B}$ and $\alpha_{2 C}$ receptors were blocked, mice were able to produce normal pharmacological responses to dexmedetomidine. Previous findings showed that dexmedetomidine mediated the hypnotic reactions of animals via $\alpha_{2 \mathrm{~A}}$ receptors in the locus coeruleus, as animals under long-term medication developed a certain drug resistance to the hypnotic effect of dexmedetomidine and calcium channel blockers were able to reverse the drug resistance (10).

Dexmedetomidine, after combining with presynaptic $\alpha_{2}$ adrenergic receptors of sympathetic nerve endings, inhibited the release of noradrenaline (8). The study also revealed that, dexmedetomidine, after combining with the postsynaptic $\alpha_{2}$ adrenergic receptors of the central nervous system were able to reduce the activity of the sympathetic nervous system, thereby lowering blood pressure and HR.

Dexmedetomidine combined with intramedullary $\alpha_{2}$ adrenergic receptors, promoted analgesia and sedation, and inhibited anxiety (7). Results of a clinical study found that, dexmedetomidine reduced the dosage of other anesthetic drugs, reduced the sympathetic excitatory effects caused by anesthesia and/or surgery, and stabilized the dynamics of blood flow (11). The sedative, hypnotic and anxiolytic effects of dexmedetomidine were mainly attributed to its combination with the genotypes of sub-types of $\alpha_{2}$ receptors in the locus coeruleus area. In mice, it was found that, when $\alpha_{2 \mathrm{~A}}$ receptors were blocked, the sedative, anaesthetic and analgesic effects of dexmedetomidine 
disappeared (12). In humans, it was found that the blood flow signals caused by dexmedetomidine were similar to the signals produced from natural sleep (13). Dexmedetomidine was able to stimulate $\alpha_{2 \mathrm{C}}$ receptors to produce anti-anxiety effects, and the mice without $\alpha_{2 \mathrm{C}}$ receptors had shortened attack latency and significantly enhanced alarm reactions (14). Dexmedetomidine also stimulated $\alpha_{2 \mathrm{~A}}$ receptors to produce analgesic effects (15), except the $\alpha_{2 \mathrm{~A}}$ receptors located above the spinal cord.

Dexmedetomidine inhibition of tracheal intubation response may be caused by its excitation of $\alpha_{2}$ adrenergic receptors, which reduce the release of catecholamine, thereby producing obvious central sedation and sympathetic inhibition effects, and reducing the cardiovascular stress responses at incubation. The study of Venn et al (16), in which 119 postoperative patients from intensive care unit (ICU) operation were given dexmedetomidine or a placebo, showed that the dosages of auxiliary sedative and analgesic drugs of patients in the dexmedetomidine group were significantly less than those of the control group, and dexmedetomidine patients were relatively cooperative and suffered less conscious pains. Another study on ICU patients who underwent mechanical ventilation indicated that, in order to achieve a better respiratory support effects, propofol-administered patients needed 3 - fold more opioid drugs than dexmedetomidine patients. The dexmedetomidine patients were also more easily awakened and more cooperative to ventilator support, and they were able to accurately recollect the lenght of stay in ICU after leaving, while propofol patients were incapable of such recollection (17).

The present study has found that dexmedetomidine reduced the dosage of other anesthetic drugs, reduced the sympathetic excitatory effects caused by anesthesia and/or surgery, and stabilized the haemodynamics (11). In addition, the effects of dexmedetomidine on respiration were much slighter (18). During the perioperative period, most patients feel fear, are anxious or worried, which inevitably results in a series of excitatory stress responses of sympathetic nerves during anaesthesia and operation, such as increased HR and blood pressure. Dexmedetomidine inhibited the excessive excitation of sympathetic nerves through activation of $\alpha_{2}$ adrenergic receptors of the central nervous system, thereby restraining the excessive release of catecholamine substances in sympathetic nerve terminals, improving the stability of hemodynamics in the perioperative period, effectively preventing or improving heart ischemia.

From a volunteer test, it was found that dexmedetomidine infusion (plasma drug concentration was $0.5 \mathrm{ng} / \mathrm{ml}$ and $5 \mathrm{ng} / \mathrm{ml}$ ) reduced myocardial perfusion, myocardial oxygen consumption, and prevented myocardial ischemia (19). Intravenous injection of dexmedetomidine before anesthesia significantly inhibited the increase of blood pressure and the acceleration of HR caused by laryngoscopy and tracheal intubation, and also reduced the dosages of anaesthetics and opioid drugs (20). A randomized comparative study on 30 patients who received awake nasotracheal intubation showed that, compared with fentanyl patients, the dexmedetomidine patients had better tolerance and more stable hemodynamics $(21,22)$.

In an earlier study from our laboratory (Junhui, Master's dissertation), it was found that the hemodynamics of patients at pump infusion of dexmedetomidine and tracheal intubation were relatively stable and ECG was not significantly changed $(23,24)$. The study also showed that dexmedetomidine reduced the secretion of catecholamine before and after awake tracheal intubation, thereby effectively preventing the adverse stress reactions of the cardiovascular system during the intubation process but not significantly affecting the patients' respiration. The result of the study indicated that, application of dexmedetomidine in awake blind tracheal intubation via oral cavity led to stable hemodynamics. In a clinical setting, the adverse reactions of dexmedetomidine mainly includes sinus tachycardia, tachycardia and even cardiac arrest, hypotension, hypertension as well as other cardiovascular diseases. Other studies have reported nausea, fever, dry mouth and other adverse reactions due to dexmedetomidine $(25,26)$.

In the present study, the two groups had no serious adverse reactions. The patients in the dexmedetomidine group had no respiratory depression, ventilation difficulties, increased blood pressure or chest wall stiffness. In comparison with the midazolam group, adverse reactions in the dexmedetomidine group were significantly reduced. Prior to surgery, the patients' specific conditions were comprehensively evaluated, especially the heart functions. For the patients with bradycardia, insufficient blood volume and cardiac conduction block, dexmedetomidine was used with caution (17). Dexmedetomidine may also be useful in protecting the nerves.

Concerning adjuvant drugs, patients of the dexmedetomidine group were given $1 \mu \mathrm{g} / \mathrm{kg}$ dexmedetomidine, which was diluted in normal saline to a final volume of $20 \mathrm{ml}$ via pump infusion for $10 \mathrm{~min}$, and followed by $0.5 \mu \mathrm{g} / \mathrm{kg}$.h as a maintenance dose. Before craniotomy and at extubation, sedative effects proved satisfactory. Most patients tolerated extubation, hemodynamics was stable, $\mathrm{SPO}_{2}$ and $\mathrm{P}_{\mathrm{ET}} \mathrm{CO}_{2}$ were not seriously affected, fluctuation of blood pressure was not obvious, no respiratory depression occurred, and the HR of several patients were significantly reduced albeit maintained over 60 beats/min, cardiac output was not affected.

By contrast, under the sedative dose $(0.05 \mathrm{mg} / \mathrm{kg})$, although patients in the midazolam group failed to inhibit a hemodynamic response at craniotomy, some patients showed obvious agitation at extubation, $\mathrm{SPO}_{2}$ and $\mathrm{P}_{\mathrm{ET}} \mathrm{CO}_{2}$ were seriously affected, and several patients had respiratory depression. In the course of intracranial hematoma clearance of $\mathrm{HCH}$, hypoxic-ischemic brain damage of the blood supply area led to the changes in the levels of many enzymes or proteins and both NSE and S100 $\beta$ were sensitive biochemical indicators of brain injury. NSE is a specific intracellular protein that exists in nerve cells and neuroendocrine cells. It monitors neuron injuries, and the changes in the level of NSE can effectively reflect the damage status of neurons. S100 $\beta$ exists in astrocytes, oligodendrocytes and other neurogliocytes and its levels reflect the damage status of neurogliocytes. The detection results of NSE and S100 $\beta$ in this study indicated that dexmedetomidine was effective for protecting the brains of $\mathrm{HCH}$ patients under craniotomy, but the specific protective mechanism needs to be further studied.

In conclusion, dexmedetomidine provided safe and effective sedation for $\mathrm{HCH}$ patients who received craniotomy. It also effectively reduced blood pressure and HR, reduced the dosage of anesthesia, alleviated the cardiovascular responses 
in anesthesia recovery period, prevented respiratory depression, and protected the brain. It is an ideal sedation adjuvant drug, and is worthy of wide application in neurosurgery.

\section{Acknowledgements}

The study was conducted with the help of a grant provided by the National Natural Science Foundation of China (project no. 81300969).

\section{References}

1. Chen ST, Chen SD, Hsu CY and Hogan EL: Progression of hypertensive intracerebral hemorrhage. Neurology 39: 1509-1514, 1989.

2. Murthy JM, Chowdary GV, Murthy TV, Bhasha PS and Naryanan TJ: Decompressive craniectomy with clot evacuation in large hemispheric hypertensive intracerebral hemorrhage. Neurocrit Care 2: 258-262, 2005.

3. Kanno T, Nagata J, Nonomura K, Asai T, Inoue T, Nakagawa T and Mitsuyama F: New approaches in the treatment of hypertensive intracerebral hemorrhage. Stroke 24: I96-I100, I107-I108, 1993.

4. Ma D, Hossain M, Rajakumaraswamy N, Arshad M, Sanders RD, Franks NP and Maze M: Dexmedetomidine produces its neuroprotective effect via the alpha 2A-adrenoceptor subtype. Eur J Pharmacol 502: 87-97, 2004.

5. Calderon LM, Guyette FX, Doshi AA, Callaway CW and Rittenberger JC: Combining NSE and S100B with clinical examination findings to predict survival after resuscitation from cardiac arrest. Resuscitation 85: 1025-1029, 2014.

6. Keating GM: Dexmedetomidine: A review of its use for sedation in the intensive care setting. Drugs 75: 1119-1130, 2015.

7. Gerlach AT and Dasta JF: Dexmedetomidine: An updated review. Ann Pharmacother 41: 245-252, 2007.

8. Bagatini A, Gomes CR, Masella MZ and Rezer G: Dexmedetomidine: Pharmacology and clinical application. Rev Bras Anestesiol 52: 606-617, 2002 (In Portuguese).

9. Su F and Hammer GB: Dexmedetomidine: Pediatric pharmacology, clinical uses and safety. Expert Opin Drug Saf 10: 55-66, 2011.

10. Sallinen J, Haapalinna A, Viitamaa T, Kobilka BK and Scheinin M: Adrenergic alpha2C-receptors modulate the acoustic startle reflex, prepulse inhibition, and aggression in mice. J Neurosci 18: 3035-3042, 1998.

11. Brown BJ, Zakhary S, Rogers L, Ellis-Stoll C, Gable D and Ramsay MA: Use of dexmedetomidine versus general anesthesia for endovascular repair of abdominal aortic aneurysms. Proc (Bayl Univ Med Cent) 19: 213-215, 2006.

12. Naaz S and Ozair E: Dexmedetomidine in current anaesthesia practice- a review. J Clin Diagn Res 8: E1-E4, 2014.
13. Coull JT, Jones ME, Egan TD, Frith CD and Maze M: Attentional effects of noradrenaline vary with arousal level: Selective activation of thalamic pulvinar in humans. Neuroimage 22: 315-322, 2004.

14. Eisenach JC, De Kock M and Klimscha W: alpha(2)-adrenergic agonists for regional anesthesia. A clinical review of clonidine (1984-1995). Anesthesiology 85: 655-674, 1996.

15. Shehabi Y, Ruettimann U, Adamson H, Innes R and Ickeringill M: Dexmedetomidine infusion for more than 24 hours in critically ill patients: Sedative and cardiovascular effects. Intensive Care Med 30: 2188-2196, 2004

16. Venn RM, Bradshaw CJ, Spencer R, Brealey D, Caudwell E, Naughton C, Vedio A, Singer M, Feneck R, Treacher D, et al: Preliminary UK experience of dexmedetomidine, a novel agent for postoperative sedation in the intensive care unit. Anaesthesia 54: 1136-1142, 1999.

17. Venn RM and Grounds RM: Comparison between dexmedetomidine and propofol for sedation in the intensive care unit: Patient and clinician perceptions. Br J Anaesth 87: 684-690, 2001.

18. Tobias JD: Dexmedetomidine: Applications in pediatric critical care and pediatric anesthesiology. Pediatr Crit Care Med 8: 115-131, 2007.

19. Snapir A, Posti J, Kentala E, Koskenvuo J, Sundell J, Tuunanen H, Hakala K, Scheinin H, Knuuti J and Scheinin M: Effects of low and high plasma concentrations of dexmedetomidine on myocardial perfusion and cardiac function in healthy male subjects. Anesthesiology 105: 902-910, quiz 1069-1070, 2006.

20. Yildiz M, Tavlan A, Tuncer S, Reisli R, Yosunkaya A and Otelcioglu S: Effect of dexmedetomidine on haemodynamic responses to laryngoscopy and intubation: Perioperative haemodynamics and anaesthetic requirements. Drugs R D 7: 43-52, 2006.

21. Chu KS, Wang FY, Hsu HT, Lu IC, Wang HM and Tsai CJ: The effectiveness of dexmedetomidine infusion for sedating oral cancer patients undergoing awake fibreoptic nasal intubation. Eur J Anaesthesiol 27: 36-40, 2010.

22. Magalhães E, Govêia CS, Ladeira LC and Espíndola BV: Relationship between dexmedetomidine continuous infusion and end-tidal sevoflurane concentration, monitored by bispectral analysis. Rev Bras Anestesiol 54: 303-310, 2004 (In Portuguese).

23. Khalil MA and Abdel AM: The impact of dexmedetomidine infusion in sparing morphine consumption in off-pump coronary artery bypass grafting. Semin Cardiothorac Vasc Anesth 17: 66-71, 2013

24. Keniya VM, Ladi S and Naphade R: Dexmedetomidine attenuates sympathoadrenal response to tracheal intubation and reduces perioperative anaesthetic requirement. Indian J Anaesth 55: 352-357, 2011.

25. Bekker AY, Basile J, Gold M, Riles T, Adelman M, Cuff G, Mathew JP and Goldberg JD: Dexmedetomidine for awake carotid endarterectomy: Efficacy, hemodynamic profile, and side effects. J Neurosurg Anesthesiol 16: 126-135, 2004.

26. Arain SR and Ebert TJ: The efficacy, side effects, and recovery characteristics of dexmedetomidine versus propofol when used for intraoperative sedation. Anesth Analg 95: 461-466, 2002. 